\title{
Article \\ Detailed Structure and Pathophysiological Roles of the IgA-Albumin Complex in Multiple Myeloma
}

\author{
Yuki Kawata ${ }^{1}$, Hisashi Hirano ${ }^{1}$, Ren Takahashi ${ }^{1}$, Yukari Miyano ${ }^{1}$, Ayuko Kimura ${ }^{1}$, Natsumi Sato ${ }^{1}$, \\ Yukio Morita ${ }^{2}$, Hirokazu Kimura ${ }^{1, *}$ and Kiyotaka Fujita ${ }^{1}$ \\ 1 Department of Health Sciences, Gunma Paz University Graduate School of Health Sciences, 1-7-1, \\ Tonyamachi, Takasaki-shi, Gunma 370-0006, Japan; kawata@paz.ac.jp (Y.K.); \\ hirano@yokohama-cu.ac.jp (H.H.); re-takahashi@paz.ac.jp (R.T.); miyano@paz.ac.jp (Y.M.); \\ ay-kimura@paz.ac.jp (A.K.); 723.sato@gmail.com (N.S.); fujita@paz.ac.jp (K.F.) \\ 2 Laboratory of Public Health II, Azabu University School of Veterinary Medicine, 1-17-71, Fuchinobe, \\ Chuo-ku, Sagamihara, Kanagawa 252-5201, Japan; y-morita@azabu-u.ac.jp \\ * Correspondence: h-kimura@paz.ac.jp; Tel.: +81-27-365-3366; Fax: +81-27-388-0386
}

Citation: Kawata, Y.; Hirano, H.; Takahashi, R.; Miyano, Y.; Kimura, A.; Sato, N.; Morita, Y.; Kimura, H.; Fujita, K. Detailed Structure and Pathophysiological Roles of the IgA-Albumin Complex in Multiple Myeloma. Int. J. Mol. Sci. 2021, 22, 1766. https://doi.org/10.3390/ ijms22041766

Academic Editor: Athanasia Mouzaki Received: 22 December 2020

Accepted: 9 February 2021

Published: 10 February 2021

Publisher's Note: MDPI stays neutral with regard to jurisdictional claims in published maps and institutional affiliations.

Copyright: (c) 2021 by the authors. Licensee MDPI, Basel, Switzerland. This article is an open access article distributed under the terms and conditions of the Creative Commons Attribution (CC BY) license (https:// creativecommons.org/licenses/by/ $4.0 /)$.

\begin{abstract}
Immunoglobulin A (IgA)-albumin complexes may be associated with pathophysiology of multiple myeloma, although the etiology is not clear. Detailed structural analyses of these proteinprotein complexes may contribute to our understanding of the pathophysiology of this disease. We analyzed the structure of the IgA-albumin complex using various electrophoresis, mass spectrometry, and in silico techniques. The data based on the electrophoresis and mass spectrometry showed that IgA in the sera of patients was dimeric, linked via the J chain. Only dimeric IgA can bind to albumin molecules leading to IgA-albumin complexes, although both monomeric and dimeric forms of $\operatorname{Ig}$ A were present in the sera. Molecular interaction analyses in silico implied that dimeric $\operatorname{Ig} \mathrm{A}$ and albumin interacted not only via disulfide bond formation, but also via noncovalent bonds. Disulfide bonds were predicted between Cys34 of albumin and Cys311 of IgA, resulting in an oxidized form of albumin. Furthermore, complex formation prolongs the half-life of $\operatorname{Ig} \mathrm{A}$ molecules in the $\operatorname{IgA}$-albumin complex, leading to excessive glycation of $\operatorname{Ig} \mathrm{A}$ molecules and affects the accumulation of $\operatorname{Ig} \mathrm{A}$ in serum. These findings may demonstrate why complications such as hyperviscosity syndrome occur more often in patients with IgA dimer producing multiple myeloma.
\end{abstract}

Keywords: multiple myeloma; IgA-albumin complex; mass spectrometry; docking simulation; oxidized albumin

\section{Introduction}

Multiple myeloma is characterized by production of abnormal and clonal immunoglobulins, including Immunoglobulin A (IgA) and Immunoglobulin G (IgG) [1]. These abnormal proteins may result in complications such as amyloidosis, nephropathy, and hyperviscosity syndrome [2,3]. Indeed, IgA produced in multiple myeloma patients has been determined to be responsible for these complications [4].

$\operatorname{Ig} \mathrm{A}$ is classified into two types, monomeric and dimeric [5]. Most monomeric $\operatorname{Ig} \mathrm{A}$ is produced by non-mucosal lymphoid tissue and is distributed in various body fluids such as serum. Meanwhile, dimeric IgA is secreted by mucosal tissues, such as the gut, mammary glands, and nasopharyngeal/oral tissues [5]. The IgA dimers bind each other at the Fc region through a protein called the J chain [5]. Dimeric IgA plays an important role in mucosal immunity against pathogens, such as bacteria and viruses. IgA can also bind to various proteins, resulting in IgA-protein complexes [6]. Indeed, previous reports have shown that IgA can bind to albumin, $\alpha$-lipoprotein, haptoglobin, anti-hemophilia protein, and $\alpha 1$-glycoprotein [6]. However, the function of these IgA-protein complexes is not clear [6].

Albumin is a common protein and broadly distributed in bodily fluids [7]. This protein acts as a carrier protein and can bind to various drugs, hormones, free fatty acids, and metal 
ions [8]. Moreover, previous reports have demonstrated that the oxidized form of albumin is associated with the pathophysiology of various diseases, including nephropathy and dyslipidemia [9]. Notably, albumin may be oxidized at specific amino acid residues, such as Cys34 [9]. However, it is not known whether oxidized albumin is associated with the pathophysiology of multiple myeloma or its complications. Moreover, the half-life of albumin in the serum (approximately 20 days) is significantly longer than that of IgA (approximately 6 days). Moreover, macromolecules such as IgA can alter the viscosity of body fluids, including serum [10,11]. Thus, IgA-albumin complexes may accumulate in body fluids during multiple myeloma, leading to complications such as hyperviscosity syndrome. Excessive glycation of the proteins including immunoglobulin may alter their functions [12]. However, pathophysiological roles of the glycated immunoglobulin in the patients with multiple myeloma is not exactly known.

In general, protein structures are closely linked to their functions. Therefore, in this study, to better understand the pathophysiology of multiple myeloma and hyperviscosity syndrome, we performed a detailed structural analysis of the IgA-albumin complex produced in multiple myeloma patients using proteomics and bioinformatics technologies.

\section{Results}

2.1. Confirmation of Albumin, IgA, and IgA-Albumin Complex in the Serum of Patients with Multiple Myeloma

To confirm the presence of albumin, IgA, and IgA-albumin complexes in sera, we performed immunofixation electrophoresis using polyclonal anti-albumin and anti-human IgA antibodies (Figure 1A-D). Using an anti-human IgA ( $\alpha$ chain) antibody, we observed a single band corresponding to IgA in the sera, while using anti-human albumin antibody, double bands of IgA-albumin complex and albumin were observed (Figure 1C). Moreover, after the purification of IgA-albumin complexes from the sera, a single band corresponding to the IgA-albumin complex was observed (Figure 1D,E). Similar data were obtained in all four samples. On the other hand, no detection of IgA-albumin complex was observed in serum from healthy patients (data not shown). These results suggest that the serum collected from patients with multiple myeloma contained IgA-albumin complexes.

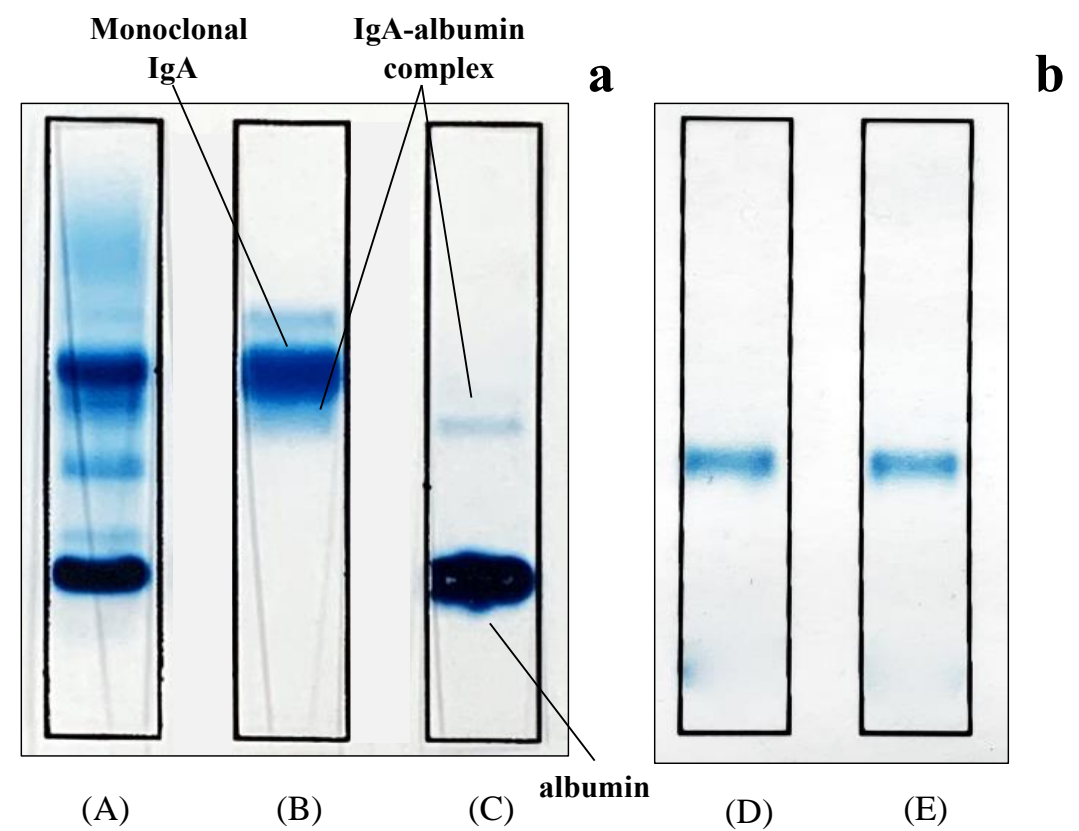

Figure 1. Immunofixation electrophoresis of patient sera (a) and of purified IgA-albumin complex (b). Proteins were analyzed by immunofixation electrophoresis using acid blue stain (lane A), anti-IgA ( $\alpha$ chain) (lanes B,D), and anti-albumin (lanes C,E) antiserum. 


\subsection{Western Blotting Analysis of IgA-Albumin Complex}

To estimate molecular weight of the IgA-albumin complexes in sera, we performed SDS-PAGE electrophoresis and subsequent Western blotting (Figure 2A,B). A single band was observed at approximately $370 \mathrm{kDa}$ in the purified samples of the IgA-albumin complexes from the sera of multiple myeloma patients. This value was approximately compatible with the molecular weight of the dimeric IgA ( $320 \mathrm{kDa})$ plus human serum albumin $(66 \mathrm{kDa})$. Moreover, to reduce these complexes, the purified samples were treated with 2-mercaptoethanol (2-ME). As a result, we observed bands at around $65 \mathrm{kDa}$ or $55 \mathrm{kDa}$ (the size of the $\alpha$-chain of IgA) (Figure 2C,D). These results implied that the IgA in these complexes was dimeric, and that the IgA-albumin complex contained disulfide bonds.

Without 2-ME

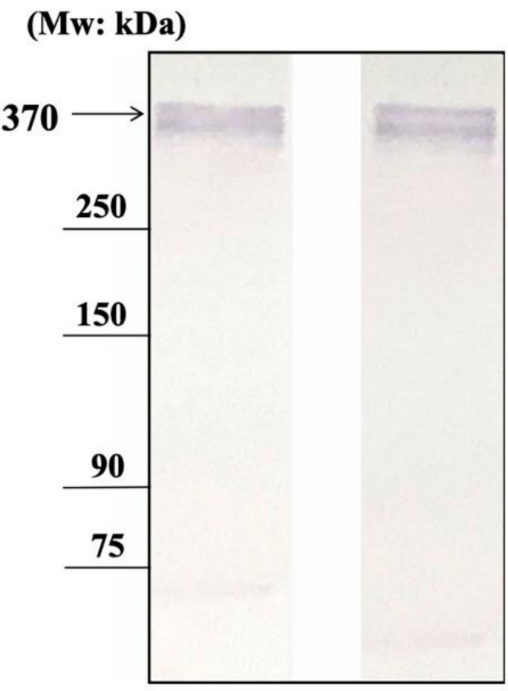

(A)

(B)
With 2-ME

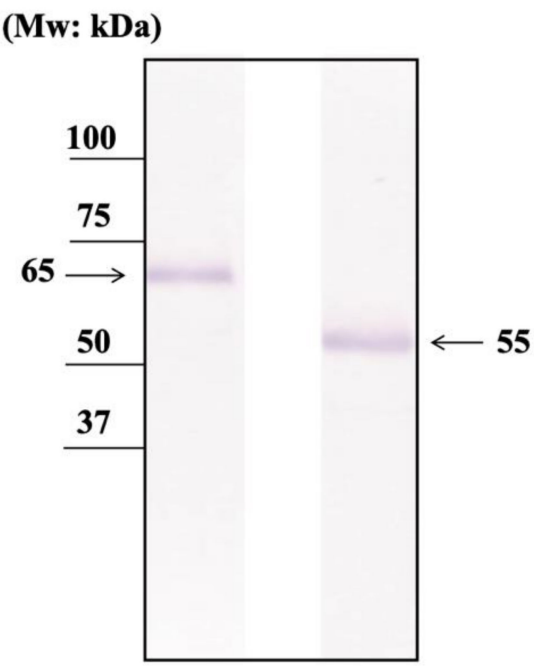

(C)

(D)

Figure 2. Western blot analysis of the purified IgA-albumin complex. IgA-albumin complexes were analyzed by SDS-PAGE and immunoblotted using anti-albumin (lanes $\mathbf{A}, \mathbf{C}$ ) and anti-IgA ( $\alpha$ chain) (lanes B,D) antiserum.

\subsection{Comprehensive Analyses of the Proteins in Sera Using Mass Spectrometry}

We analyzed proteins found in the sera of patients with multiple myeloma and normal adults using mass spectrometry (Table 1 and Supplementary Tables S1-S4). When purified IgA-albumin complexes cut from the gels after SDS-PAGE were digested and analyzed by mass spectrometry, the J chain (P01591) was detected in addition to IgA $\alpha$ chain (P01876), $\kappa$ chain (P01834), and albumin (P02768). When monoclonal IgA purified from the same patient's serum was digested in solution and analyzed by mass spectrometry, IgA $\alpha$ chain and $\mathrm{k}$ chains were detected, but albumin and the J chain were not. These results indicate that only dimer-type IgA with the J chain forms IgA-albumin complexes. In addition, when IgA and albumin were purified from the sera of healthy individuals, in which monomer-type IgA comprised most of the serum, no albumin or J chain proteins were detected in the digested IgA by mass spectrometry, and no IgA was detected in the digested albumin. Moreover, $\alpha 1$-antitrypsin (P01009), $\alpha 2$-macroglobulin (P01023), and complement C3 (P01024) are present in large amounts in serum, and are likely to be detected nonspecifically during purification because they are large molecular weight proteins that increase with inflammation. 
Table 1. Proteins identified by mass spectrometry from each purification step (IgA-albumin complex, monoclonal IgA, albumin and polyclonal IgA).

\begin{tabular}{|c|c|c|c|c|c|}
\hline Analyzed Sample Names & Protein IDs & Identified Protein Names & Gene Names & Unique Peptides & $\begin{array}{l}\text { Mol. Weight * } \\
\text { [kDa] }\end{array}$ \\
\hline \multirow{5}{*}{$\begin{array}{l}\text { IgA-albumin complex } \\
\text { from Patients sera }\end{array}$} & P02768 & Serum albumin & ALB & 21 & 69.37 \\
\hline & P01876 & Ig alpha- 1 chain $C$ region & IGHA1 & 7 & 37.65 \\
\hline & P01834 & Ig kappa chain $C$ region & IGKC & 7 & 11.77 \\
\hline & P01591 & Immunoglobulin J chain & IGJ & 7 & 18.10 \\
\hline & P01009 & Alpha-1-antitrypsin & SERPINA1 & 8 & 46.74 \\
\hline \multirow{6}{*}{$\begin{array}{c}\text { Monoclonal IgA } \\
\text { (albumin no-bound)from } \\
\text { Patients sera }\end{array}$} & P01876 & Ig alpha- 1 chain $C$ region & IGHA1 & 11 & 37.65 \\
\hline & P01834 & Ig kappa chain $C$ region & IGKC & 7 & 11.77 \\
\hline & P01024 & Complement C3 & $\mathrm{C} 3$ & 7 & 187.15 \\
\hline & P01023 & Alpha-2-macroglobulin & A2M & 5 & 163.29 \\
\hline & P01009 & Alpha-1-antitrypsin & SERPINA1 & 4 & 46.74 \\
\hline & P02647 & Apolipoprotein A-I & APOA1 & 4 & 30.78 \\
\hline \multirow{5}{*}{$\begin{array}{l}\text { Albumin } \\
\text { from Normal sera }\end{array}$} & P02768 & Serum albumin & ALB & 45 & 69.37 \\
\hline & P01023 & Alpha-2-macroglobulin & $\mathrm{A} 2 \mathrm{M}$ & 8 & 163.29 \\
\hline & P02787 & Serotransferrin & TF & 12 & 77.06 \\
\hline & P10909 & Clusterin & CLU & 6 & 52.49 \\
\hline & P00738 & Haptoglobin & $\mathrm{HP}$ & 6 & 45.21 \\
\hline \multirow{4}{*}{$\begin{array}{l}\text { Polyclonal IgA } \\
\text { from Normal sera }\end{array}$} & P01876 & Ig alpha- 1 chain $C$ region & IGHA1 & 9 & 37.65 \\
\hline & P01834 & Ig kappa chain $\mathrm{C}$ region & IGKC & 4 & 11.77 \\
\hline & P01023 & Alpha-2-macroglobulin & A2M & 8 & 163.29 \\
\hline & P01009 & Alpha-1-antitrypsin & SERPINA1 & 7 & 46.74 \\
\hline
\end{tabular}

Note: Proteins identified by only one peptide were discarded, and only proteins that matched at least two unique peptides (Andromeda score $\geq 100$ ) were included. Detailed peptide data are shown in the supplement (Supplemental Tables S1-S4). * The molecular weights as reported in the Uniprot database.

\subsection{Docking Simulation Analyses and Molecular Modeling of IgA-Albumin Complex}

To analyze molecular interactions between $\operatorname{IgA}$ and albumin, we performed in silico docking simulations. In the resultant complex structure, the Cys 311 residue of IgA was in close proximity to the Cys34 residue of albumin with the distance between the two sulfur atoms being $9.8 \AA$ (Figure 3a). Many noncovalent interactions between the albumin and $\mathrm{J}$ chain were also observed (Figure $3 \mathrm{~b}$ ), and the binding affinity was estimated as $-9.5 \mathrm{kcal} / \mathrm{mol}$. These observations strongly suggest that the IgA molecules dimerized via $\mathrm{J}$ chain can form a stable complex with an albumin molecule.

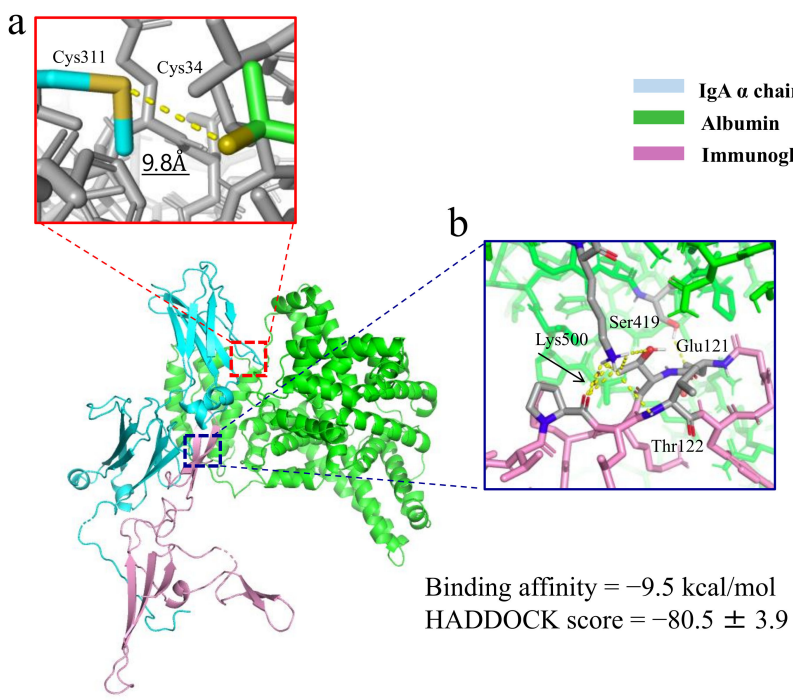

Figure 3. Predicted structure of the IgA-albumin complex (colored cartoon). In the enlarged panel, the Cys311 residue of IgA was in close proximity to the Cys34 residue of albumin (a). The other panel suggests that there are many noncovalent bonds between the J chain and albumin (b). An arrow indicates noncovalent bond. 


\subsection{Fructosamine Levels in the Sera of Patients with Multiple Myeloma Characterized by Abnormal IgA Production}

Significantly elevated fructosamine levels in the serum of all patients were observed $(467 \pm 25 \mu \mathrm{M}$, reference values; $245 \pm 19 \mu \mathrm{M})$. These results suggested that glycation of proteins in the sera was increased.

\section{Discussion}

In this study, we performed detailed molecular analyses of the IgA-albumin complex contained in the sera of the patients with multiple myeloma. First, IgA in the sera from these patients was revealed to be dimeric in nature, bound by the J chain protein. Second, although both monomeric and dimeric forms of $\operatorname{IgA}$ were found in the sera, only dimeric IgA could bind to albumin molecules to form IgA-albumin complexes. Third, simulated molecular interaction analyses suggested that these interactions between dimeric IgA and albumin occurred via not only disulfide but also noncovalent bonds (Figure 3). Additionally, specific cysteine residues, Cys311 of IgA and Cys34 of albumin, were predicted to form the disulfide bond, leading to an oxidized form of albumin. Oxidized albumin has been associated with the pathophysiology of complications of multiple myeloma, although the etiology of these diseases is not fully understood [13]. Moreover, significantly elevated fructosamine levels were observed in the sera of these patients, suggesting that IgA and accumulated protein-protein complexes may have increased half-lives in the sera. Glycation of IgA caused by prolongation of the half-life may also contribute to increased fructosamine levels. Finally, increased levels of IgA-albumin complexes due to prolonged half-life may promote hyperviscosity syndrome, a major complication in patients with multiple myeloma characterized by abnormal IgA production. To the best of our knowledge, this is the first study suggesting that dimeric IgA in multiple myeloma may associate with the complication of hyperviscosity syndrome.

Monomeric IgA is an immunoglobulin approximately $150 \mathrm{kDa}$ in size. When dimerized via the J chain, the resulting IgA structure is around $300 \mathrm{kDa}$, and these molecules become resistant to proteolytic enzymes such as trypsin and airway mucosal serin protease (i.e., Transmembrane protease serin2 [TMPRSS2]) [14]. Dimeric IgA is secreted by various mucosal tissues, including in the gastrointestinal and respiratory tracts, and may play an important role in mucosal immunity against various pathogens [15]. Increased dimeric $\operatorname{IgA}$ in the serum may be associated with various complications of multiple myeloma [16]. In this study, we observed that dimeric IgA could bind to albumin, leading to the formation of IgA-albumin complexes. Moreover, our simulations predicted detailed molecular interactions between $\operatorname{IgA}$ and albumin in this complex.

Albumin is a common major protein distributed in bodily fluids, including sera. Albumin protein can bind various materials, including drugs, bilirubin, metal ions, and other proteins, and acts as a functional transporter [17]. Previous reports have shown that albumin has three binding sites (site I, II, and III) [18,19]. Moreover, an amino acid residue, Cys34, can bind to the $\mathrm{SH}$ group of ligands or to nitric oxide [9]. In the present study, we found that albumin could bind to dimeric IgA in the sera of patients with multiple myeloma. Moreover, we found that dimeric IgA is able to form stable complex with albumin by the docking simulation. These results are partly compatible with an earlier report [20]; however, that report did not identify the binding site between IgA and albumin [19]. Previous reports have also suggested that albumin oxidized at the Cys34 residue may be associated with diseases such as nephropathy and dyslipidemia [9]. The formation of a disulfide bond between IgA and albumin leads to oxidized albumin [21]. Therefore, the IgA-oxidized albumin complex may be associated with the pathophysiology of complications in patients with multiple myeloma characterized by abnormal IgA production, although the physiological roles of oxidized albumin have not been elucidated [21].

Then what interactions are responsible for the formation of IgA-albumin complex? The distance ( $9.8 \AA$ ) obtained from the HADDOCK analysis was the one between 2 sulfur atoms of Cys34 of albumin and Cys311 of IgA. The binding energy reported by HADDOCK 
software refers to the sum of all interactions between the atoms of albumin and the atoms of IgA, but not the particular binding energy between Cys34 of albumin and Cys311 of IgA. Indeed, as shown in Figure 3b and Supplemental Figure S1, many intermolecular interactions were observed between albumin and the J chain of IgA. Moreover, as shown in Figure 2, the IgA-albumin complex dissociated by the addition of 2-mercaptoethanol, strongly suggesting that the binding of the complex was of covalent (disulfide) nature. The dissociation constant between albumin and IgA can be calculated as $1.08 \times 10^{-7} \mathrm{M}$ from the binding energy, $-9.5 \mathrm{kcal} / \mathrm{mol}$, reported by the HADDOCK software. This value suggests that the binding is strong enough to form a stable IgA-albumin complex. We thus infer that the internal motion of the complex enables the mutual approach of the 2 sulfur atoms at $9.8 \AA$ distance in the docked structure to form an -S-S- bond $(2.05 \AA)$. We do not expect electrostatic attraction between the 2 sulfur atoms, because the sulfur atom in a cysteine residue is always charged negative ( -1 in the deprotonated state and -0.57 in the protonated state) [22].

The half-life of serum albumin is estimated to be around 20 days, while the half-life of $\operatorname{IgA}$ is around 6 days $[10,11]$. Therefore, when IgA molecules bind to albumin, the half-life of the IgA may be prolonged, leading to excessive glycation [23]. Moreover, a previous report suggested that fructosamine levels in sera were significantly elevated in multiple myeloma patients with abnormal IgA production [24]. Indeed, fructosamine levels were found to be significantly elevated in sera in the present study. Hyperviscosity syndrome is a common complication in patients with multiple myeloma [25]. This complication may correlate with disease survival [26] because of the prolonged half-life albumin-bound IgA. Previous reports suggested that hyperviscosity syndrome in multiple myeloma may be responsible for increased blood cells (erythrocytes, leukocytes, and platelets) and macromolecules (mainly immunoglobulins) in the blood [25]. Previous reports also suggested that blood hyperviscosity may be partly responsible for increased IgA-protein complexes in patients with multiple myeloma [27]. These findings can be compatible with our results. Moreover, previous reports showed that increased IgA levels in the sera of patients with multiple myeloma are associated with hyperviscosity syndrome [28]. In these reports, IgA levels of patients with greater than $4000 \mathrm{mg} / \mathrm{dL}$ [28] were similar to those in our data from patients with greater than $4200 \mathrm{mg} / \mathrm{dL}$. To actually measure blood viscosity, relatively large amounts of blood samples are needed (around $7 \mathrm{~mL}$ ) [29]; unfortunately, one limitation of the present study is that we did not have adequate sample volume to measure serum viscosity.

In conclusion, we present here a hypothesis as to why complications such as hyperviscosity syndrome frequently accompany dimeric IgA production in multiple myeloma. Our results and speculations may contribute to the understanding of the pathophysiology of multiple myeloma and disease prognosis.

\section{Materials and Methods}

\subsection{Subjects}

Sera were obtained from four patients ranging in age from 52 to 84 (69.8 \pm 13.7 years) with multiple myeloma characterized by abnormal IgA production. All four sera from patients with high IgA (greater than $4000 \mathrm{mg} / \mathrm{dL}$ ). These patients were not clinically diabetic and had blood sugar of $98.5 \pm 35.4 \mathrm{mg} / \mathrm{dL}$. Normal sera were also collected from 10 adults ranging in age from 18 to 35 ( $25.3 \pm 6.9$ years). Informed consent was obtained from all participants, which was obtained from the subjects or their legal representatives upon sample donation. All patient data were anonymized. Because of the lack of written informed consent, the present study protocols were deliberated by the Ethics Committee on Human Medical Research of Gunma Paz University (Gunma, Japan), which ruled that this study did not infringe upon the patient's rights, and was approved by the research ethics committee (approval no. PAZ-18-9). All methods were performed in accordance with the approved guidelines. 


\subsection{Confirmation of IgA-Albumin Complexes in the Sera of Patients with Multiple Myeloma by Immunofixation Electrophoresis}

Serum was diluted 21-fold with phosphate-buffered saline (PBS). Electrophoresis was performed in $0.06 \mathrm{M}$ barbital buffer $(\mathrm{pH} 8.6)$ using a commercially available kit (Quick gel IFE kit, HERENA Laboratory, Urawa, Japan). Serum $(3 \mu \mathrm{L})$ was applied and electrophoresed at a constant voltage of $90 \mathrm{~V}$ for $20 \mathrm{~min}$. After electrophoresis, the gel was incubated with anti-human $\operatorname{IgA}(\alpha$ chain) and anti-human albumin antibodies for $10 \mathrm{~min}$. After reaction, the gel was stained with acid blue dye for $2 \mathrm{~min}$ and decolorized with 10\% acetic acid to minimize background staining.

\subsection{Purification of IgA, IgA-Albumin Complex, and Free Albumin from Serum}

Purification steps for IgA, the IgA-albumin complex, and free albumin are shown in Figure 4. First, proteins were concentrated from serum by affinity chromatography using Cibacron Blue F3G-A columns (Amersham Biosciences, Little Chalfont, Britain) (Figure 4a). The column washed with $0.05 \mathrm{M}$ Tris- $\mathrm{HCl}$ buffer ( $\mathrm{pH}$ 7.0) containing $0.1 \mathrm{M}$ potassium chloride, and the bound proteins (albumin, monoclonal $\operatorname{IgA}$, and IgA-albumin complex) were eluted by $0.05 \mathrm{M}$ Tris- $\mathrm{HCl}$ buffer $(\mathrm{pH} 7.0)$ containing $1.5 \mathrm{M}$ potassium chloride. Proteins were concentrated with an Amicon Minicon-B15 concentrator (Amicon Division, Beverly, MA), and then purified with Jacalin-Agarose (Funakoshi Corporation, Tokyo, Japan) (Figure $4 \mathrm{~b}$ ). The unbound protein (free albumin) was eluted with $1 \mathrm{M}$ phosphate buffer ( $\mathrm{pH} 7.2)$, and the bound proteins (IgA-albumin complex and monoclonal IgA) were eluted with $0.1 \mathrm{M}$ phosphate buffer ( $\mathrm{pH}$ 7.2) containing 0.8 M galactose. Finally, the IgA-albumin complex and the monoclonal IgA were separated using an anti-human albumin antibody affinity column (Affi-Gel Hz Hydrazide Gel (BIO-RAD, California, America)) (Figure 4c). Unbound protein (monoclonal IgA) was eluted by $0.02 \mathrm{M}$ Tris- $\mathrm{HCl}$ buffer (pH 7.5) containing 0.005\% Briji-35, and the bound protein (IgA-albumin complex) was eluted with a $0.1 \mathrm{M}$ glycine hydrochloride buffer $(\mathrm{pH} 2.8)$.

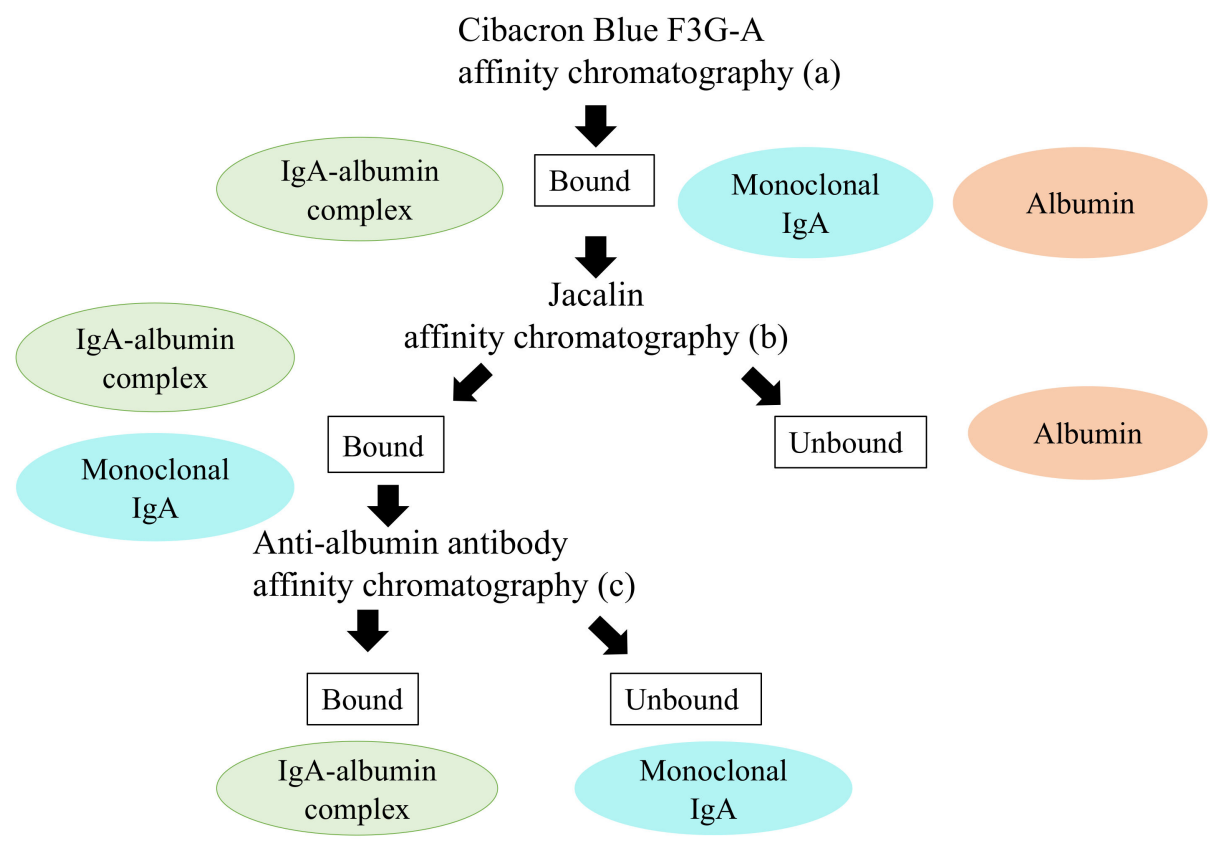

Figure 4. Procedure for purification of each protein from serum. Procedures are represented as (a-c).

\subsection{SDS-PAGE and SDS-Agarose-Polyacrylamide Hybrid Gel Electrophoresis Analysis}

A total of $10 \mu \mathrm{g}$ of purified IgA-albumin was mixed with sample buffer $(0.375 \mathrm{M}$ Tris$\mathrm{HCl}$ buffer (pH 8.8), 5\% 2-Mercaptoethanol, 2\% SDS, 20\% glycerol). SDS-polyacrylamide gel electrophoresis (PAGE) was performed using $5-20 \%$ polyacrylamide gradient gels. 
SDS-agarose-polyacrylamide hybrid gels containing $5 \mathrm{M}$ urea were prepared by mixing $4 \%$ acrylamide and $1 \%$ agarose for separation of high-molecular-weight proteins [30]. The purified samples were diluted with $0.5 \mathrm{M}$ Tris- $\mathrm{HCl}$ buffer $(\mathrm{pH}$ 6.8) and then mixed with sample buffer without reducing agent ( $4 \%$ SDS, $20 \%$ glycerol, $0.02 \%$ bromophenol blue in $0.1 \mathrm{M}$ Tris- $\mathrm{HCl}$ buffer ( $\mathrm{pH}$ 6.8)). Each diluted sample was heat-denatured at $95{ }^{\circ} \mathrm{C}$ for $5 \mathrm{~min}$, and electrophoresis was performed at a constant current of $20 \mathrm{~mA}$ for $2 \mathrm{~h}$.

\subsection{Western Blotting}

Proteins separated by SDS-PAGE were transferred to polyvinylidene difluoride (PVDF) membranes (MERCK, Tokyo, Japan) for $90 \mathrm{~min}$ at $200 \mathrm{~mA}$ constant current using a Trans-Blot SD cell (BIO-RAD, California, America). Immunostaining was performed using rabbit anti-human polyclonal antiserum (MBL, Nagoya, Japan), for primary immunoreaction, and Horseradish peroxidase (HRP)-labeled goat anti-rabbit IgG $(\mathrm{H}+\mathrm{L})$ serum (MBL) for secondary immunoreaction. After washing the membranes with PBS-T ( $\mathrm{pH}$ 7.4), bound antibodies were detected with POD Immunostain Set (FUJIFILM Wako, Osaka, Japan).

\subsection{In-Gel Digestion}

Gel lanes were cut into $1 \mathrm{~mm}$ square gel pieces. Gel pieces were decolorized with $50 \mathrm{mM} \mathrm{NH}_{4} \mathrm{HCO}_{3} / 60 \%$ acetonitrile $(\mathrm{ACN})$ at $37^{\circ} \mathrm{C}$ for $30 \mathrm{~min}$ four times and lyophilized using a vacuum freeze-dryer (Techcorp FD-3-85-MP). Proteins were digested with trypsin solution $(25 \mathrm{ng} / \mu \mathrm{L})$ at $37^{\circ} \mathrm{C}$ for $16 \mathrm{~h}$. Peptide digests were desalted and concentrated using C18 stage tips prior to LC-MS/MS analysis [31]

\subsection{Liquid Chromatography/Tandem Mass Spectrometry (LC-MS/MS)}

LC-MS/MS analysis was performed as reported previously [32]. Digested peptides were separated by a 115 -min acetonitrile gradient from $4 \%$ to $40 \%$ using an Ultimate 3000 nano-HPLC system (Dionex Softron, Germany) with a Nanoscale C18 capillary LC column (Acclain PepMap 100 C18 column, $75 \mu \mathrm{m}$ id, $150 \mathrm{~mm}$ length, $3 \mu \mathrm{m}$ particle size, $100 \AA$ A). The liquid was directly electrosprayed with electrospray ionization source in positive ion mode using a SilicaTip PicoTip nanospray emitter (10 $\mu \mathrm{m}$ id, top non-coated; New Objective Inc., Woburn, MA, USA) and analyzed on an LTQ Orbitrap Velos (Thermo Fisher Scientific, Bremen, Germany). MS/MS analysis was performed in data-dependent scanning mode with a full-range scan ( $\mathrm{m} / \mathrm{z}$ range from 350 to 1200), followed by product ion scans for the 15 most intense ions selected from the MS-scan spectra. Peptides were identified using MaxQuant ver.1.6.2.10 [33]. Peptides were queried against the Uniprot human database using default settings with slight modifications as follows: main search peptide tolerance of $6 \mathrm{ppm}$ (http://www.uniprot.org/). Finally, peptides with fewer than two missed trypsin cleavages, a false discovery rate $<0.01$, and an Andromeda score $>100$ were selected for analysis. Proteins identified by only one peptide were discarded, and matches with at least two unique peptides (Andromeda score $\geq 100$ ) were considered to be accurately identified [34].

\subsection{Docking Simulation}

Molecular docking simulation was used to identify the predicted binding site of the monoclonal IgA-albumin complex. The Fc regions and J chain from dimeric IgA (2QTJ) [35] and albumin (1AO6) [36] in the open configuration were downloaded from the protein data bank. The solvated docking software HADDOCK [37] was used to dock albumin with IgA in the presence of the J chain component. After docking simulation, PRODIGY software was used to predict the binding affinity for IgA and albumin. The average docking scores and residues predicted to take part in the interaction were also determined. 


\subsection{Measurement of Fructosamine in the Serum}

Serum fructosamine levels in four patients with multiple myeloma characterized by abnormal IgA production were measured with Spotchem EZ SP-4430 (Arkray, Tokyo, Japan) as previously described [38].

Supplementary Materials: The following are available online at https://www.mdpi.com/1422-006 7/22/4/1766/s1. Supplemental Table S1: Peptides identified from the purified IgA-albumin complex from patient sera. Supplemental Table S2: Peptides identified from the purified monoclonal IgA from patient sera. Supplemental Table S3: Peptides identified from the purified albumin from normal sera. Supplemental Table S4: Peptides identified from the purified polyclonal IgA from normal sera. Supplemental Figure S1: Noncovalent molecular interactions between IgA and albumin.

Author Contributions: Conceptualization, K.F. and H.H.; data curation, Y.M. (Yukari Miyano); formal analysis, Y.K., A.K., N.S., and R.T.; methodology, Y.M. (Yukio Morita) and Y.K.; supervision, K.F.; validation, Y.K.; writing—original draft, Y.K. and H.K.; writing—review and editing, K.F. and H.K. All authors have read and agreed to the published version of the manuscript.

Funding: This research received no external funding.

Institutional Review Board Statement: The study was conducted according to the guidelines of the Declaration of Helsinki and approved by the Institutional Review Board (or Ethics Committee) of Gunma Paz University (protocol code PAZ18-9 and date of 29 May 2018).

Informed Consent Statement: Informed consent was obtained from all subjects involved in the study.

Data Availability Statement: The protein structural data in Figure 3 are available online at https: //www.rcsb.org/structure/2QTJ and https://www.rcsb.org/structure/1AO6.

Acknowledgments: The authors thank Kaori Wakamatsu (Division of Molecular Science, Graduate School of Science and Technology, Gunma University) for useful discussions. We also thank Hiromu Kurusu (Gunma Paz University) for his support and encouragement of this research.

Conflicts of Interest: The authors declare no conflict of interest.

\section{Abbreviations}

$\begin{array}{ll}\text { ACN } & \text { Acetonitrile } \\ \text { Cys } & \text { Cysteine } \\ \text { HRP } & \text { Horseradish peroxidase } \\ \text { IgA } & \text { Immunoglobulin A } \\ \text { IgG } & \text { Immunoglobulin G } \\ \text { ME } & \text { Mercaptoethanol } \\ \text { PBS } & \text { Phosphate-buffered saline } \\ \text { PVDF } & \text { Polyvinylidene difluoride } \\ \text { SDS-PAGE } & \text { Polyacrylamide gel electrophoresis } \\ \text { TMPRSS2 } & \text { Transmembrane protease serin 2 }\end{array}$

\section{References}

1. Kyle, R.A. Monoclonal gammopathy of undetermined significance and smoldering multiple myeloma. Eur. J. Haematol. 2009, 43, 70-75. [CrossRef]

2. Gertz, M.A. Immunoglobulin light chain amyloidosis: 2016 update on diagnosis, prognosis, and treatment. Am. J. Hematol. 2016, 91, 947-956. [CrossRef]

3. Srour, M.; Kassab, I.; Matta, H.; Elkak, A. Histidine based adsorbents for selective removal of monoclonal immunoglobulin IgM antibodies from Waldenstrom's macroglobulinemia patient sera: A preliminary study. J. Chromatogr. B 2013, 932, 1-5. [CrossRef]

4. Herrmann, S.M.; Govani, M.V.; Fidler, M.E.; Nasr, S.H.; Klink, D.; Amin, C.; Leung, N.; Fervenza, F.C. Recurrence of monoclonal IgA lambda glomerulonephritis in kidney allograft associated with multiple myeloma. Clin. Nephrol. 2015, 84, 241-246. [CrossRef]

5. De Sousa-Pereira, P.; Woof, J.M. IgA: Structure, Function, and Developability. Antibodies 2019, 8, 57. [CrossRef]

6. Tomasi, T.B., Jr.; Hauptman, S.P. The binding of $\alpha-1$ antitrypsin to human IgA. J. Immunol. 1974, 112, 2274-2277. [PubMed]

7. Janice, T.B. Serum Albumin and Globulin, Clinical Methods: The History, Physical, and Laboratory Examinations, 3rd ed.; Walker, H.K., Hall, W.D., Hurst, J.W., Eds.; Butterworths: Boston, MA, USA, 1990; pp. 497-499. 
8. Czub, M.P.; Venkataramany, B.S.; Majorek, K.A.; Handing, K.B.; Porebski, P.J.; Beeram, S.R.; Suh, K.; Woolfork, A.G.; Hage, D.S.; Shabalin, I.G.; et al. Testosterone meets albumin—the molecular mechanism of sex hormone transport by serum albumins. Chem. Sci. 2019, 10, 1607-1618. [CrossRef] [PubMed]

9. Nagumo, K.; Tanaka, M.; Chuang, V.T.G.; Setoyama, H.; Watanabe, H.; Yamada, N.; Kubota, K.; Tanaka, M.; Matsushita, K.; Yoshida, A.; et al. Cys34-cys teinylated human serum albumin is a sensitive plasma marker in oxidative stress-related chronic diseases. PLoS ONE 2014, 9, e85216. [CrossRef]

10. Jaquet, H.; Bloom, B.; Cebra, J.J. The reductive dissociation of rabbit immune globulin in sodium dodecylsulfate. J. Immunol. 1964, 92, 991-1007. [PubMed]

11. Steiner, D.; Merz, F.W.; Sonderegger, I.; Gulotti-Georgieva, M.; Villemagne, D.; Phillips, D.J.; Forrer, P.; Stumpp, M.T.; Zitt, C.; Binz, H.K. Half-life extension using serum albumin-binding DARPin ${ }^{\circledR}$ domains. Protein Eng. Des. Sel. 2017, 30, 583-591. [CrossRef]

12. Wei, B.; Berning, K.; Quan, C.; Zhang, Y.T. Glycation of antibodies: Modification, methods and potential effects on biological functions. MAbs 2017, 9, 586-594. [CrossRef]

13. Bruschi, M.; Candiano, G.; Santucci, L.; Ghiggeri, G.M. Oxidized albumin. The long way of a protein of uncertain function. Biochim. Biophys. Acta (BBA) Gen. Subj. 2013, 1830, 5473-5479. [CrossRef]

14. Li, Y.; Jin, L.; Chen, T.-X. The Effects of Secretory IgA in the Mucosal Immune System. BioMed Res. Int. 2020, 2020, 1-6. [CrossRef]

15. Herich, R. Is the role of IgA in local immunity completely known? Food Agric. Immunol. 2016, 28, 223-237. [CrossRef]

16. Sallustio, F.; Curci, C.; Di Leo, V.; Gallone, A.; Pesce, F.; Gesualdo, L. A New Vision of IgA Nephropathy: The Missing Link. Int. J. Mol. Sci. 2019, 21, 189. [CrossRef]

17. Johnson-Davis, K.L.; Dasgupta, A. Chapter 11-Special issues in therapeutic drug monitoring in patients with uremia, liver disease, and in critically ill patients. In Clinical Challenges in Therapeutic Drug Monitoring, 1st ed.; Clarke, W., Dasgupta, A., Eds.; Elsevier: Amsterdam, The Netherlands, 2016; pp. 245-260.

18. Anraku, M.; Yamasaki, K.; Maruyama, T.; Kragh-Hansen, U.; Otagiri, M. Effect of Oxidative Stress on the Structure and Function of Human Serum Albumin. Pharm. Res. 2001, 18, 632-639. [CrossRef]

19. Yamasaki, K.; Chuang, V.T.G.; Maruyama, T.; Otagiri, M. Albumin-drug interaction and its clinical implication. Biochim. Biophys. Acta (BBA) Gen. Subj. 2013, 1830, 5435-5443. [CrossRef] [PubMed]

20. Fujita, K.; Kameko, F.; Kato, Y.; Fukushima, M.; Okumura, N.; Terasawa, F.; Sugano, M.; Yamauchi, K.; Sato, H.; Kameko, M.; et al. Mechanism of IgA-albumin complex formation that affects the fructosamine assay. J. Electrophor. 2006, 50, 19-23. [CrossRef]

21. Nakashima, F.; Shibata, T.; Kamiya, K.; Yoshitake, J.; Kikuchi, R.; Matsushita, T.; Ishii, I.; Giménez-Bastida, J.A.; Schneider, C.; Uchida, K. Structural and functional insights into S-thiolation of human serum albumins. Sci. Rep. 2018, 8, 1-12. [CrossRef]

22. Freddie, R.S., Jr.; Leslie, B.P.; Jacquelyn, S.F. Electrostatics of cysteine residues in proteins: Parameterization and validation of simple model. Proteins 2012, 80, 2583-2591. [CrossRef]

23. Andersen, J.T.; Daba, M.B.; Berntzen, G.; Michaelsen, T.E.; Sandlie, I. Cross-species Binding Analyses of Mouse and Human Neonatal Fc Receptor Show Dramatic Differences in Immunoglobulin G and Albumin Binding. J. Biol. Chem. 2010, 285, 4826-4836. [CrossRef]

24. Fujita, K.; Curtiss, L.K.; Sakurabayashi, I.; Kameko, F.; Okumura, N.; Terasawa, F.; Tozuka, M.; Katsuyama, T. Identification and Properties of Glycated Monoclonal IgA That Affect the Fructosamine Assay. Clin. Chem. 2003, 49, 805-808. [CrossRef] [PubMed]

25. John, L.; Fahey, M.D. Serum Hyperviscosity Syndrome. JAMA 1965, 192, 464-467. [CrossRef]

26. Borgman, C.J. Concomitant multiple myeloma spectrum diagnosis in a central retinal vein occlusion: A case report and review. Clin. Exp. Optom. 2016, 99, 309-312. [CrossRef] [PubMed]

27. Hashimoto, T. Hyperviscosity Symdrome. J. Jpn. Soc. Int. Med. 1995, 84, 1096-1099. [CrossRef]

28. Alkner, U.; Hansson, U.B.; Lindström, F.D. Factors affecting IgA related hyperviscosity. Clin. Exp. Immunol. 1983, 51, 617-623.

29. Tomiyama, Y.; Brian, J.E.; Todd, M.M. Plasma viscosity and cerebral blood flow. Am. J. Physiol. Circ. Physiol. 2000, 279, H1949-H1954. [CrossRef]

30. Noro, M.; Oh-Ishi, M. Heat-induced complex formation of lactoferrin analyzed by an SDS-agarose-polyacrylamide (SDS-AGPAGE) hybrid gel. Electrophor. Lett. 2015, 59, 21-24. [CrossRef]

31. Rappsilber, J.; Mann, M.; Ishihama, Y. Protocol for micro-purification, enrichment, pre-fractionation and storage of peptides for proteomics using StageTips. Nat. Protoc. 2007, 2, 1896-1906. [CrossRef] [PubMed]

32. Kimura, A.; Arakawa, N.; Hirano, H. Mass Spectrometric Analysis of the Phosphorylation Levels of the SWI/SNF Chromatin Remodeling/Tumor Suppressor Proteins ARID1A and Brg1 in Ovarian Clear Cell Adenocarcinoma Cell Lines. J. Proteome Res. 2014, 13, 4959-4969. [CrossRef]

33. Cox, J.; Mann, M. MaxQuant enables high peptide identification rates, individualized p.p.b.-range mass accuracies and proteomewide protein quantification. Nat. Biotechnol. 2008, 26, 1367-1372. [CrossRef]

34. Kimura, A.; Kurata, Y.; Nakabayashi, J.; Kagawa, H.; Hirano, H. N-Myristoylation of the Rpt2 subunit of the yeast 26S proteasome is implicated in the subcellular compartment-specific protein quality control system. J. Proteom. 2016, $130,33-41$. [CrossRef] [PubMed]

35. Bonner, A.; Furtado, P.B.; Almogren, A.; Kerr, M.A.; Perkins, S.J. Implications of the Near-Planar Solution Structure of Human Myeloma Dimeric IgA1 for Mucosal Immunity and IgA Nephropathy. J. Immunol. 2008, 180, 1008-1018. [CrossRef] [PubMed] 
36. Sugio, S.; Kashima, A.; Mochizuki, S.; Noda, M.; Kobayashi, K. Crystal structure of human serum albumin at $2.5 \AA$ A resolution. Protein Eng. Des. Sel. 1999, 12, 439-446. [CrossRef] [PubMed]

37. De Vries, S.J.; Van Dijk, M.; Bonvin, A.M.J.J. The HADDOCK web server for data-driven biomolecular docking. Nat. Protoc. 2010, 5, 883-897. [CrossRef]

38. Trumel, C.; Diquélou, A.; Germain, C.; Palanché, F.; Braun, J. Comparison of measurements of canine plasma creatinine, glucose, proteins, urea, alanine aminotransferase, and alkaline phosphatase obtained with Spotchem SP 4430 and Vitros 250 analyzers. Res. Vet Sci. 2005, 79, 183-189. [CrossRef] [PubMed] 